\title{
Contribución indígena a la cartografía del Alto Ucayali a fines del siglo XVII
}

Contribution indigène à la cartographie du Haut Ucayali à la fin du XVIIe siècle Indigenous contribution to the cartography of the Upper Ucayali by the end of the XVII ${ }^{\text {th }}$ century

\section{Roberto Chauca Tapia}

\section{(2) OpenEdition}

Journals

Edición electrónica

URL: http://journals.openedition.org/bifea/7488

DOI: 10.4000/bifea.7488

ISSN: 2076-5827

Editor

Institut Français d'Études Andines

Edición impresa

Fecha de publicación: 1 abril 2015

Paginación: 117-138

ISSN: 0303-7495

\section{Referencia electrónica}

Roberto Chauca Tapia, «Contribución indígena a la cartografía del Alto Ucayali a fines del siglo XVII », Bulletin de l'Institut français d'études andines [En línea], 44 (1) | 2015, Publicado el 08 mayo 2015, consultado el 06 noviembre 2020. URL : http://journals.openedition.org/bifea/7488 ; DOI : https:// doi.org/10.4000/bifea.7488

\section{(@) $\odot \Theta$}

Les contenus du Bulletin de l'Institut français d'études andines sont mis à disposition selon les termes de la licence Creative Commons Attribution - Pas d'Utilisation Commerciale - Pas de Modification 4.0 International. 


\title{
Contribución indígena a la cartografía del Alto Ucayali a fines del siglo XVII*
}

\author{
Roberto Chauca Tapia**
}

\section{Resumen}

Este artículo examina la participación de nativos conibo en la producción del conocimiento geográfico y cartográfico del Alto Ucayali en 1686. La evidencia proviene de una serie de reportes y mapas derivados de un litigio entre los franciscanos de Lima y los jesuitas de Quito por la posesión de una misión entre los conibo. Esta investigación resalta el importante rol que los conibo jugaron en la expedición franciscana al Alto Ucayali y la naturaleza consensual de la cartografía de la Amazonía colonial.

Palabras clave: cartografía histórica, etnohistoria, producción de conocimiento, conibo, franciscanos, Alto Ucayali

\section{Contribution indigène à la cartographie du Haut Ucayali à la fin du XVIIe siècle}

\section{Résumé}

Cet article examine la participation des indigènes Conibo dans la production de connaissance géographique et cartographique du Haut Ucayali en 1686. La documentation provient d'un ensemble de rapports et de cartes résultant d'un différend entre les Franciscains de Lima et les Jésuites de Quito sur la possession d'une mission parmi les Conibo. Cette recherche met l'accent sur le rôle important

Este artículo es producto de una investigación más amplia financiada gracias a la Beca Andina de Apoyo a la Investigación del Instituto Francés de Estudios Andinos, la Dissertation Fieldwork Grant de la Wenner-Gren Foundation y la International Dissertation Research Fellowship del Social Science Research Council.

** Candidato al doctorado, Departamento de Historia, Universidad de Florida, 25 Keene-Flint Hall, Gainesville, FL 32611, USA. E-mail: rchauca@ufl.edu 
que les Conibo jouèrent dans l'expédition franciscaine du Haut Ucayali et dans la nature consensuelle de la cartographie de l'Amazonie coloniale.

Mots-clés : cartographie historique, ethnohistoire, production de connaissance, Conibo, Franciscains, Haut Ucayali

\section{Indigenous contribution to the cartography of the Upper Ucayali by the end of the XVII ${ }^{\text {th }}$ century}

\section{Abstract}

This article examines the participation of Conibo natives in the process of geographic and cartographic knowledge of the Upper Ucayali in 1686. The evidence comes from a series of reports and maps produced in a lawsuit between the Franciscans of Lima and the Jesuits of Quito contesting the possession of a mission among the Conibo. This research underlines the important role that Conibo

Keywords: historical cartography, ethnohistory, knowledge making, Conibo, Franciscans, Upper Ucayali

\section{INTRODUCCIÓN}

La Amazonía se convirtió en un importante centro de producción de conocimiento cartográfico y geográfico durante la Colonia. Misioneros fueron enviados a dicha región como agentes evangelizadores y civilizadores de la corona española. La producción de mapas y relatos de viaje se convirtieron en una herramienta necesaria que los frailes usaron para registrar las sociedades y los territorios que eran el centro de su labor misionera. Sin embargo, los frailes estaban llegando como simples aprendices a una región ya habitada y conocida por sus pobladores locales. En consecuencia, la producción del conocimiento espacial dependió de la relación establecida entre ambos grupos de actores. El problema es que los nativos amazónicos han permanecido como figuras decorativas dentro de estudio de la cartografía de la Amazonía occidental colonial porque los mapas y relatos, producidos generalmente por misioneros, dan la impresión que la labor cartográfica solo estuvo a cargo de los frailes. No obstante, una relectura de las fuentes permite determinar y analizar la participación indígena en los mapas y exploraciones misioneras de la Amazonía colonial. En este artículo se analiza, en particular, la expedición franciscana al Ucayali en 1686, cuya información deriva de una serie de reportes y mapas presentados entre 1686 y 1694 que fueron parte de un litigio entre los franciscanos de Lima y los jesuitas de Quito por el control del Alto Ucayali (Oliver, 1754). Ambas partes argumentaron que tenían posesión sobre una misión llamada San Miguel o Santísima Trinidad de acuerdo a fuentes franciscanas o jesuitas, respectivamente. Este sitio estaba habitado por nativos conibo ${ }^{1}$ y localizado cerca a la confluencia de los ríos Ucayali y Pachitea ${ }^{2}$.

Las partes involucradas en este pleito presentaron tres mapas para complementar la evidencia de sus supuestas posesiones en la Amazonía occidental ${ }^{3}$. Hasta el presente, estos mapas no han sido estudiados4. Eruditos de la historia de la cartografía franciscana del Amazonas han analizado sobre todo los mapas impresos en los siglos XVIII y XIX, cuando estos alcanzaron una mayor circulación. Además, no se examinó la participación indígena en esta cartografía (Arbesmann, 1945; Craig, 1972; Cuesta, 1986; 1992; 1997; Gridilla, 1943; Heras, 1980; 1992: 303327). El mapa, como objeto de estudio, tiene la particularidad de presentar un estado del conocimiento geográfico como si fuera un producto acabado y total; sin embargo, obscurece al mismo tiempo el proceso de operaciones que lo hizo posible (de Certeau, 1984: 121). Este artículo busca explorar de nuevo aquellas operaciones, en donde hubo participación indígena, que hicieron posible la producción cartográfica del Ucayali a fines del siglo XVII. Algunos estudiosos señalaron que la expedición franciscana de 1686 al Ucayali recibió la ayuda de nativos conibo y en particular de uno de sus curacas, Felipe Cayampay (Espinoza, 2007: 208-209; Heras, 1989: 86-88; Morin, 1998: 306; Raimondi, 1876, vol. 2: 216-228; Tibesar, 1989: 42-43). Sin embargo, el rol que jugaron los conibo en la producción del conocimiento cartográfico y geográfico de dicha región no recibió mayor análisis.

Dos problemas que puede presentar el estudio de la contribución cartográfica indígena son, por un lado, mostrar a los nativos como los únicos productores del conocimiento cartográfico y a los misioneros como meros receptores. En el caso del Ucayali, no existen referencias a mapas hechos o usados por los mismos conibo. Esta investigación se basa en materiales producidos por los frailes y los soldados que los acompañaron en su excursión a dicha región. Warren DeBoer ha notado los riesgos relacionados al uso de registros históricos sobre este grupo étnico, escritos por foráneos que tendían a exaltar la cultura de los conibo (DeBoer 1986: 233, 238). En el caso de la cartografía del Ucayali la situación es distinta porque mientras los informes franciscanos tendieron a borrar toda huella de participación nativa en la expedición al Ucayali, los reportes de los soldados indican lo contrario. Entonces, cruzar referencias de ambos grupos de fuentes permite

1 En adelante, conibo se refiere al nombre de la etnia y Conibos al del pueblo.

Extractos de este documento han sido publicados en Maúrtua (1907, vol. 6: 305-356), Biedma (1981: 91-167), Biedma et al. (1989: 97-154, 171-230, 269-282), Heras, ed. (1979; 1980; 1985). 3 Los extractos publicados de este documento y editados por Julián Heras provinieron del manuscrito original de1694, propiedad de Rubén Vargas Ugarte, quien lo donó al Archivo del Convento de Ocopa en los años 1950 (Heras, 1989: 92) y donde se conserva hasta la actualidad bajo el código Libro $\mathrm{N} .{ }^{\circ}$ 75. No obstante, pude constatar personalmente que el original no incluye los tres mapas manuscritos. Además, Antonino Tibesar indicó que el había consultado uno de estos mapas no en Ocopa sino en la mapoteca del Ministerio de Relaciones Exteriores del Perú (Tibesar, 1989: 74-75, n. ${ }^{\circ}$ 135). Esto corrobora que el manuscrito conservado en la Cancillería, que es una copia hecha en 1754 , es el único que contiene dichos mapas.

4 Estos mapas fueron publicados, aunque sin mayor análisis, en Cuesta (1997: 498-506). 
estudiar el rol de los conibo en la producción cartográfica de esta región, aunque siempre como parte de expediciones promovidas por los agentes de la corona española5. El segundo problema tiene que ver con enfocarse holísticamente en los nativos como un grupo genérico de productores de conocimiento cartográfico. Lo interesante, más bien, es que estas fuentes permiten diferenciar ciertos individuos o expertos conibo que se convirtieron en proveedores del conocimiento espacia que hizo posible los mapas y exploraciones franciscanos. En suma, este artículo busca explicar la construcción espacial del Alto Ucayali como resultado de una negociación entre saberes indígenas y occidentales y de esta manera enfatizar la naturaleza consensuada de la cartografía colonial del Amazonas.

\section{EL LITIGIO JESUITA-FRANCISCANO Y LA CARTOGRAFÍA DEL \\ UCAYALI EN LOS AÑOS 1680}

En 1682, el padre Juan Lorenzo Lucero, Superior de las misiones de Maynas, indicó que los jesuitas de la misión de La Laguna o Cocama, cerca a la confluencia de los ríos Huallaga y Marañón, ya habían establecido contactos con algunas sociedades del Ucayali (Lucero, 1682: 81v). Mientras tanto, el padre Manuel Biedma señaló que los franciscanos habían recibido noticias de aquellas etnias desde 1673, cuando iniciaron incursiones en tierras de los indios asháninka o campa, alrededor de las cuencas de los ríos Urubamba, Apurímac y Ene, al sur del Ucayali (Oliver, 1754 $225 \mathrm{v}-231 \mathrm{v})$. Situado entre estas dos áreas, el Alto Ucayali era el hogar de una serie de sociedades; sin embargo, fuentes misioneras revelan que los conibo eran uno de los grupos más dominantes de la región, conocidos por sus habilidades en la navegación fluvial (Amich, 1854: 89; Maroni, 1988: 111). Ellos eran uno de los grupos con quien lidiar por el control de esta área. En ese entonces, el Ucayali era conocido también como la puerta de entrada al recóndito reino de Enin, supuestamente ubicado en las selvas orientales del Cuzco. Fuentes jesuitas y franciscanas de los años 1680 indican que este alejado reino, de riquezas y poblaciones exuberantes, estaba gobernado por incas huidos del Cuzco (Lucero, 1683: 18; Oliver, 1754 226r-227r, 257v-258r). De este modo, el control del Alto Ucayali habría permitido a los frailes tener acceso a recursos tanto humanos como materiales ${ }^{6}$.

Jesuitas y franciscanos se dieron cuenta de que la evangelización del Ucayali iniciaría un conflicto entre ambas órdenes. Por ello, los franciscanos pidieron a las autoridades virreinales de Lima interceder en este asunto. El 7 de mayo de 1686 el Comisario General de la orden franciscana del Perú, Félix de Como, pidió al virrey del Perú, Melchor de Navarra y Rocaful, que demarcara el área misionera de los jesuitas desde la misión de Cocama hasta la boca del Ucayali, dejando el Alto Ucayali bajo dominio franciscano hasta la misión que tenían

5 Para otros casos que estudian la participación indígena en la cartografía colonial en diversas partes del continente americano, véanse Barr (2011), Mundy (1996), Short (2009) y Whitehead (1998). 6 El padre Lucero (1685) luego negó la existencia de depósitos de oro en la cuenca occidental de Amazonas. entre los campa (Oliver, 1754: 3r-3v). El 14 de mayo, el fiscal Juan Gonzales señaló que las autoridades de Lima conocían muy poco sobre el tema y ordenó que representantes de ambas órdenes enviaran mapas y reportes indicando sus posesiones en el Ucayali. Asimismo, pidió a los corregidores de ciudades cercanas como Jaén, Cuenca, Chachapoyas y Cajamarquilla que enviaran sus pareceres sobre este litigio (Oliver, 1754: 4r).

El 29 de julio el escribano del Cabildo y Real Hacienda de Quito, Lope Antonio de Urquía, presentó la respuesta de la comunidad jesuita. Esta incluía una carta del Presidente del Colegio jesuita de Quito, Juan Martínez Rubio, quien pedía posponer el envío del mapa y reporte puesto que ellos estaban todavía esperando el regreso del padre Lucero, quien había pasado más de veinticuatro años por esas tierras y había contactado muchas etnias de los márgenes del Ucayali. Según Rubio, Lucero, «quien con mas pleno conocimiento podra informar y dar las noticias convenientes y necessarias para que se haga el mapa, y demarcacion, que manda Su Excelencia y traherá en su compañía otras personas practicas en dichas missiones, sus rios y poblaciones» (Oliver, 1754: 6r-6v). Parece claro que la producción y transmisión del conocimiento geográfico y espacial estaban restringidas para unos pocos, como el padre Lucero, cuya experiencia en el Ucayali lo convertía en la persona más idónea para elaborar dicho mapa y reporte. Empero, se indicó que Lucero traería a «otras personas practicas» en el Ucayali para fundamentar la posición jesuita. ¿Quiénes eran estos «practicos»? Nada más se dice al respecto. Sin embargo, este tema es indicativo de la naturaleza cooperativa de la empresa cartográfica y geográfica la cual, a pesar de estar ligada a ciertos individuos, requería de consensos.

El 22 de agosto el Corregidor de Chachapoyas, Vicente de Bustillo y Navarro, informó que había delegado la tarea de presentar el reporte sobre el litigio del Ucayali a gobernador de Lamas, Juan López de Vardales y Herrera, quien estaba más cerca del área en conflicto. En su reporte, Vardales describió la ocupación misionera en las cuencas del Huallaga y Ucayali. Mientras el Huallaga parecía estar compartido por ambas órdenes - la parte meridional correspondía a los franciscanos-, el Ucayali es descrito como un dominio jesuita. En el reporte se indicó que los jesuitas habían evangelizado el Ucayali por más de 40 años, ocupando un área extensa desde la boca del río hasta las misiones de nativos campa y piro. También se señaló que, nueve meses atrás, un franciscano que, saliendo de Tarma había intentado entrar en territorio campa, observó las misiones que los jesuitas habían establecido con antelación en el Ucayali. Por último, Vardales reportó que no habría conflicto entre ambas órdenes puesto que ellos parecían conocer claramente sus posiciones a lo largo de este río (Oliver, 1754: 12v-14r).

Para complementar su reporte, Vardales incluyó un mapa (fig. 1)7. Este fue el resultado de una consulta previa con «mas de quinze testigos peritos y experimentados en

ALMREP, VPE-015. Este mapa originalmente correspondió al folio 13 del legajo del pleito jesuitafranciscano. Este y los otros dos mapas estuvieron incluidos en el legajo; sin embargo, luego fueron separados y archivados de manera separada en la mapoteca del ALMREP. 


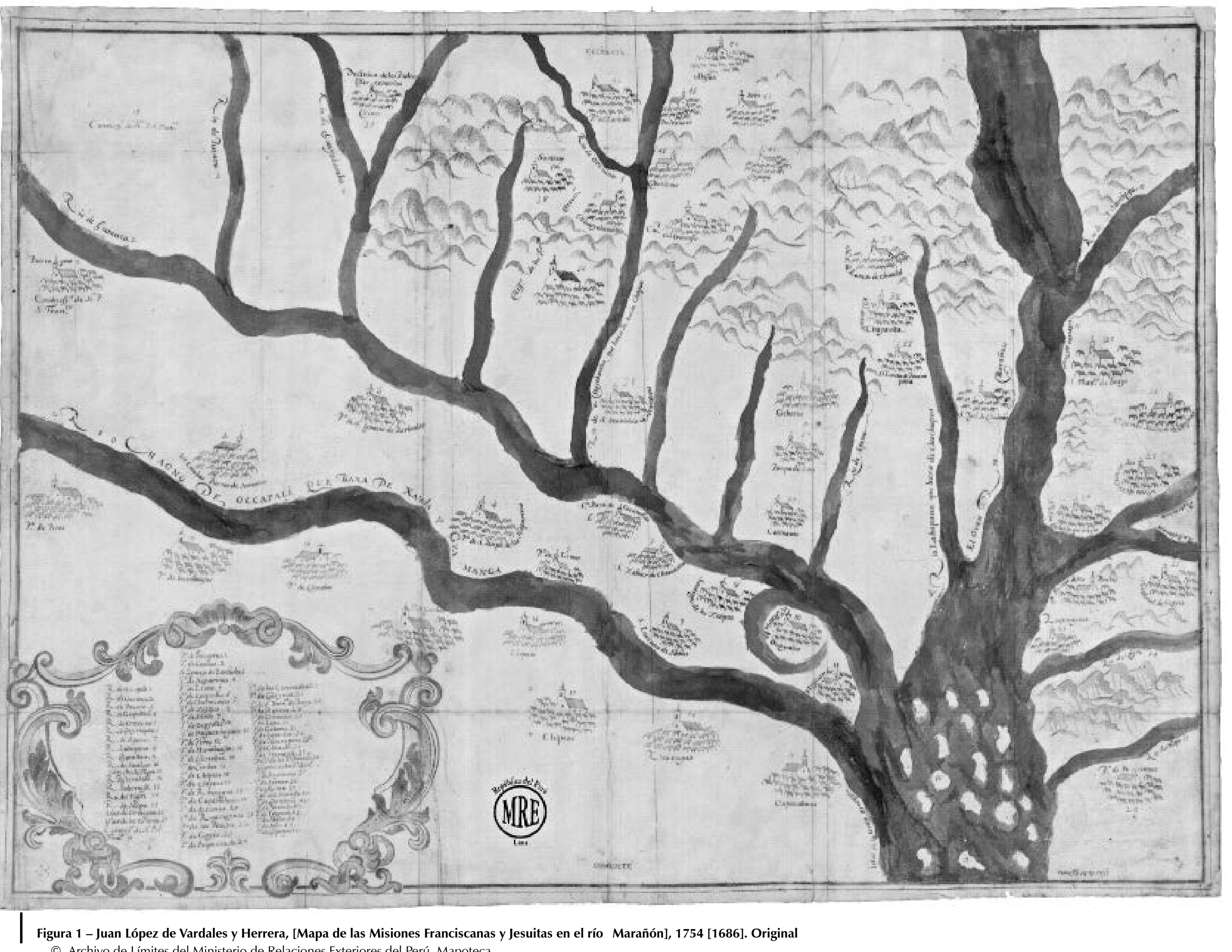


dichas missiones» (Oliver, 1754: 14r). El corregidor Bustillo le había pedido que se reuniera con prácticos en las misiones franciscanas del Huallaga y jesuitas del Marañón. Vardales señaló que él había efectuado dicha reunión, y que, a pesar de su propio conocimiento de dichos territorios, siguió solo sus recomendaciones (Oliver, 1754: 12v). Aunque él no mencionó quiénes fueron esos peritos, esto ayuda a convalidar la noción de que la cartografía de la Amazonía colonial estuvo basada en un proceso consensual. Vardales sabía, por otro lado, que su mapa no era profesional. Él mencionó que era solo un bosquejo que necesitaba ser mejorado por un piloto. A pesar de ello, Vardales aseguró que su mapa ayudaría a clarificar el litigio misionero (Oliver, 1754: 12v, 14v). En efecto, este mapa muestra en detalle la ubicación de los pueblos y misiones a lo largo del Huallaga y Ucayali, así como los ubicados en el Marañón hasta el punto donde aquellos dos ríos desembocan en este. Las misiones franciscanas se ubican solamente en la parte meridional del Huallaga. Y, al igual que en su reporte, su presencia es nula en el Ucayali.

El 10 de septiembre el gobernador de Jaén, Diego de Rivera, señaló que Antonio García de Soarez, párroco de Santiago de las Montañas, era una persona más idónea para informar sobre el pleito misionero en el Ucayali. En mayo pasado, Soarez había terminado de realizar una visita oficial a las misiones jesuitas en los ríos Marañón, Pastaza y Huallaga, y dio un informe detallado de las misiones, nombres de los padres y número de bautizados desde la fundación de cada misión (Soarez, 1686: 135v-140). El padre Lucero confirmó la visita de Soarez a Maynas (Oliver, 1754: 17r-17v). En septiembre, Soarez dio un nuevo informe en el cual señalaba que había enviado al gobernador Rivera un mapa de aquellas misiones, mapa que estaba sin refinar debido a la falta de instrumentos en Jaén y durante su visita por las misiones (Oliver, 1754: 14v-15r).

El mapa de Soarez (fig. 2) muestra diversos poblados y misiones a lo largo de Marañón, Huallaga y otros tributarios meridionales del Amazonas, así como aquellos ubicados en sus afluentes septentrionales8. Se describe, sobre todo, la presencia jesuita a lo largo de la Amazonía occidental, lo cual tiene sentido puesto que Soarez había visitado aquellas regiones cerca de un año antes del inicio del litigio. Con respecto al Ucayali, el mapa de Soarez no es muy claro. Primero, el curso de este río no es delineado en su totalidad; solo aparece su curso bajo, cuando desemboca en el Amazonas. Cerca de esta confluencia hay una misión sin nombre, la cual probablemente corresponda a la misión jesuita entre los conibo. Si seguimos el curso hacia el Alto Ucayali, el mapa muestra una segunda y última misión, que es la de los franciscanos. En su reporte de septiembre, sin embargo, Soarez había proporcionado información muy detallada sobre la locación de los jesuitas y franciscanos en el Ucayali. Él señaló que la misión jesuita estaba localizada 20 días río arriba desde la misión de cocama. Estaba a cargo del padre Enrique Richter y habitada por nativos conibo y manamahovos. Desde este sitio, 30 leguas río arriba, estaban localizadas las misiones de los franciscanos, hasta las tierras de
Andamarca. Debido a la distancia entre ambas órdenes, Soarez indicó que había pleno espacio para que ambos pudieran evangelizar (Oliver, 1754: 15v).

En febrero de 1687, representantes de la orden franciscana encabezados por su Comisario General, Féliz de Como, enviaron sus alegatos. Ellos intentaron probar que sus misioneros se habían establecido primero entre los conibo y explicaron las razones que les obligaron a dejar esta misión a los jesuitas. Ellos argumentaron que los hermanos Juan de Navarrete y Pedro Laureano, junto al capitán Juan Álvarez, habían salido desde Andamarca, y luego de navegar por el Perené entraron al Ucayali. Tomaron posesión del pueblo de Conibos en septiembre de 1684, dejaron unas cruces de madera como muestra de ello y prometieron a los nativos que volverían para evangelizarlos. Después de dos o tres meses, ante las noticias de la llegada de los franciscanos, los jesuitas enviaron una expedición a dicha población y, antes de partir, dejaron construida una iglesia como símbolo de su estadía. En septiembre de 1686, los franciscanos Manuel Biedma y Francisco de Huerta, junto al capitán Bartolomé de Veraum, entre otros, navegaron de vuelta a Conibos, pero esta vez ellos encontraron la iglesia jesuita, lo cual era un mensaje claro que este sitio ya no era más suyo. En octubre, ellos decidieron dejar Conibos luego de recibir noticias que los jesuitas planeaban bajar para esta misión con una tropa militar no solo para ocupar dicho pueblo sino para continuar hasta el puerto de San Luis de Perené, en busca de un grupo de nativos piro y campa que acababan de asesinar al hermano Francisco Herrera (Richter, 1686: 114). En suma, la posición franciscana era que la misión de Conibos fue ocupada primero por sus misioneros. Entonces, todo el Ucayali, desde el Perené hasta Conibos debía pertenecerles a ellos (Oliver, 1754: 17v-29r).

Este punto de vista estuvo expresado en el mapa que presentó la orden seráfica en el litigio (fig. 3)9. Este mapa muestra todo el Alto Ucayali, hasta la misión de Conibos por el norte. Por el sur incluye los tributarios meridionales del Ucayali, en especial los ríos Ene y Perené, con sus cursos delineados hasta los puntos de partida de los misioneros franciscanos en Tarma y Jauja ${ }^{10}$. No están delineados ni el Huallaga ni el Marañón. Este mapa fue evidentemente hecho para demostrar que la totalidad del Alto Ucayali estaba bajo dominio franciscano. En primer lugar, están señaladas solamente las misiones seráficas, pero no hay mención de la presencia jesuita en esa parte de la Amazonía. En segundo lugar, los nativos campa aparecen ocupando prácticamente todo el margen izquierdo del Ucayali, mientras que en el mapa de Vardales ellos solo ocupaban una misión. Reportes de los expedicionarios franciscanos señalan la presencia campa a lo largo de todo el Ucayali (Oliver, 1754: $122 v, 148 r, 187 r)$. Y puesto que los campa eran evangelizados por los franciscanos, esto significaba que toda el área ocupada por estos nativos debía estar bajo dominio seráfico. En todo caso, ¿̇cuáles fueron los medios cartográficos que los misioneros utilizaron para legitimizar su descripción espacial de los campa?

9 ALMREP, VPE-017. Este mapa originalmente correspondió al folio 30 del legajo.

${ }^{10}$ La autoría del tercer mapa es desconocida. Antonino Tibesar señaló que su autor podría ser e capitán Francisco Rojas (Tibesar, 1989: 74, n. ${ }^{\circ} 135$ ) 


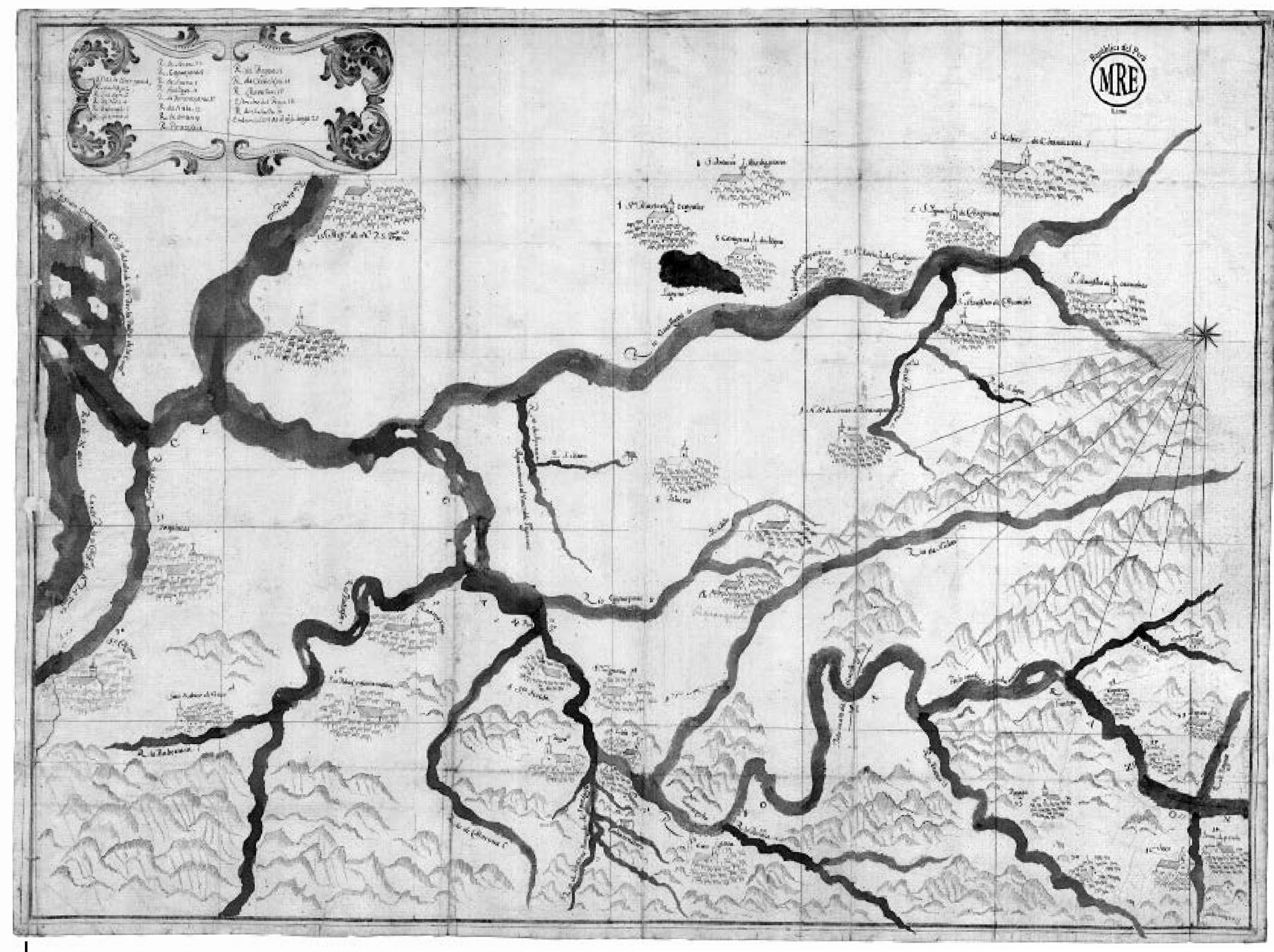

Figura 2 - Antonio García de Soarez, [Mapa de las Misiones Franciscanas y Jesuitas en los ríos Huallaga y Marañón], 1754 [1686]. Original (c) Archivo de Límites del Ministerio de Relaciones Exteriores del Perú. Mapoteca 


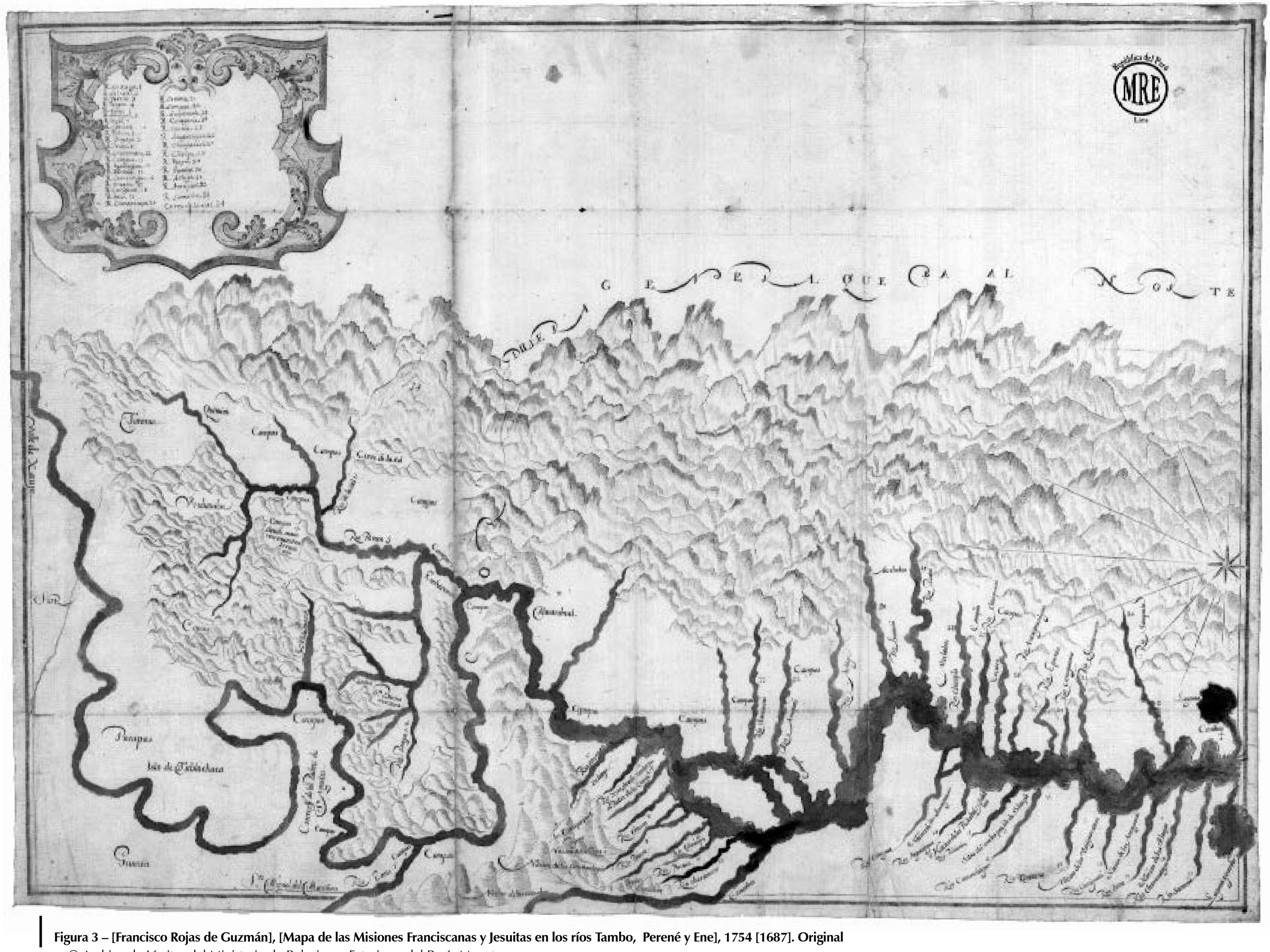

(๔) Archivo de Límites del Ministerio de Relaciones Exteriores del Perú. Mapoteca 
Los franciscanos trataron de describir el proceso de elaboración de su mapa en los términos más adecuados posibles para hacer legítima no solo la ubicación de los nativos campa sino el de todas las sociedades, territorios y ríos descritos en él. Ellos hicieron esto enfatizando la participación de varios actores en la producción de este mapa. En relación a su autoría, el capitán Pedro Velasco, miembro de la expedición a Conibos en 1686, indicó que este mapa lo «hizieron los padres con gran cuidado y diligencia». No obstante, él también señaló que en el mapa estaban demarcados todos «los parajes, rios, navegaciones, poblaciones, y sitios, que reconocieron assi de vista, como por noticias de los indios» (Oliver, 1754: 26v). Asimismo, el capitán Francisco de la Fuente, otro expedicionario, indicó que este mapa:

donde quedaban señalados, y declarados todos los parajes, rios, poblaciones, y naciones descubiertas en la ocasión de la entrada y salida [de Conibos], que es quanto por vista y por noticias pudieron saber, según el corto tiempo que estuvieron en aquellos parajes, y que dicho mapa se tuviesse por fiel y verdadero por haverse hecho y reconocido de comun acuerdo de todos os que entraron conformandose á lo que vieron y supieron por noticias repetidas por diferentes personas, de aquellos indios principales, y demas gentes que se comunicaron (Oliver, 1754: 20v).

El proceso de elaboración consensuado de este mapa fue confirmado por otros miembros de la expedición franciscana como el padre Francisco Huerta y los capitanes Bartolomé de Veraum, Juan Álvarez y Francisco Rojas (Oliver, 1754: 19r, 24v-25r, 28v, 29r). La yuxtaposición de diferentes saberes provistos por frailes, soldados y nativos parece haber sido una práctica frecuente en la cartografía misionera, la cual proveía de una base ancha de legitimidad ante las complicaciones que la práctica cartográfica y exploratoria traía consigo.

\section{PARTICIPACIÓN INDÍGENA EN LA CARTOGRAFÍA Y EXPLORACIÓN DEL UCAYALI EN 168}

Pero, ¿quiénes eran aquellos «indios principales» que habían participado en el grupo que «de comun acuerdo» había cartografiado el Ucayali? Indígenas han pasado desapercibidos cuando se ha discutido la cartografía colonial del Amazonas¹1. Las fuentes examinadas aquí son relevantes pues indican la participación de varios actores en la cartografía del Ucayali. Y aunque estos no fueron individualmente identificados, las fuentes señalan la colaboración nativa en la exploración del espacio cartografiado. A fin de cuentas, la exploración y la cartografía son partes del mismo proceso puesto que el reconocimiento del espacio permite a su vez su descripción gráfica en la forma de un mapa. Es decir, en tanto nativos participaron de la exploración del Ucayali, su influencia en la producción cartográfica puede ser inferida. El mapa franciscano ayudará a clarificar este asunto.

${ }^{11}$ Neil Whitehead (1998) intentó proveer un análisis histórico de la cartografía indígena amazónica, pero su estudio no salió de un enfoque etnográfico. Sin embargo, proveyó interesantes claves para leer indicios de cartografía nativa.
Aunque las fuentes no indican que este mapa fue realizado por indios conibo, su colaboración en la expedición franciscana al Ucayali y el contexto de la producción cartográfica sí lo sugieren. Sin embargo, cuando se estudia la participación cartográfica indígena, el análisis debe basarse en una lectura meticulosa de fuentes que fueron producidas no por los nativos sino por los frailes y soldados miembros de la expedición. Y a pesar de haber participado en la misma excursión, las fuentes producidas por estos dos grupos responden a dos marcos de interpretación distintos sobre la participación indígena en la cartografía del Alto Ucayali. Reportes militares reconocen explícitamente la participación nativa en la construcción espacial del Ucayali. En cambio, los informes misioneros subestiman y hasta niegan el rol de los conibo en dicho proceso ${ }^{12}$. Sin embargo, si cruzamos datos de ambas fuentes, es posible trazar una imagen más balanceada y completa de la participación e influencia indígena en la exploración y cartografía del Alto Ucayali.

Información más detallada de la expedición a Conibos de 1686 se encuentra en reportes presentados entre 1691 y 1692 por el padre Domingo Álvarez de Toledo, procurador de la orden franciscana en el Perú, y los capitanes Bartolomé de Veraum y Francisco Rojas de Guzmán que habían acompañado a la expedición para proteger a los padres. Estos indican los nombres de aquellos indios principales que participaron o proveyeron valiosa información al grupo franciscano durante su excursión al Ucayali. Estos fueron el curaca de los conibo, Saniguani, así como otros principales conibo como Cayampay, Sanampico, Pusinampay, y un indio cristiano «de Quito» llamado Lorenzo o Bernardo, quien vino a morar a Conibos luego de haber sido criado por misioneros jesuitas (Oliver, 1754: 70v-71r, 137v-138r, 141r, 154r, 279r-279v). En su reporte, el capitán Veraum mencionó que luego de salir de Jauja y zarpar del puerto de San Luis de Perené, la expedición llegó a San Buenaventura el 24 de julio de 1686 (Oliver, 1754: 70r). Luego, el 4 de septiembre, la expedición llegó a San Miguel de Conibos, donde estuvieron por veinticuatro días (Oliver, 1754: 71r). La descripción de los territorios, ríos y sociedades del Alto Ucayali que hizo el capitán Veraum es interesante pues da varios indicios que sugieren la participación nativa en la exploración del Ucayali. Después de salir de Buenaventura, Veraum señaló que,

abaxo del encuentro destos dos rios [Perene y Ene], [al Ucayali] le entran otros dos de menos aguas de la parte del oriente á la mano izquierda de la cordillera general nombrados Mazaroberi y Caroazati, donde habitan algunos Andes gentiles de nacion Campas, y mas abaxo de Mazarober hai otro rio, que se nombra Cayapo por la parte de la mano derecha, y le habitan los Piros, y tiene su cazique curaca nombrado Mangoli. Mas abajo

${ }^{12}$ Tzvetan Todorov (1984: 146-167) en su análisis del «gran debate» entre Juan Ginés de Sepúlveda y Bartolomé de las Casas presenta una distinción similar entre el discurso secular del humanista que, aunque jerárquico, presta atención a las particularidades indígenas, y el discurso religioso del dominico que, aunque igualitario, niega la otredad nativa. Los reportes y mapas del gobernador de Lamas y del cura de Santiago de las Montanas, discutidos anteriormente, también reflejan la misma distinción pues mientras el gobernador refiere que recibió la colaboración de más de quince prácticos, el cura no mencionó haber recibido ningún tipo de ayuda. 
del rio Cayapo hai otro rio grande [...] y es su nombre el famoso Taraba, y rio arriba en distancia de tres dias de camino, le habitan quatro naciones, que son Comavos, Robonaguas, Pichavos, y Soboivos, y tienen un curaca y cazique á quien le obedecen, que su nombre es Mano, y tienen onse pueblos en forma de republica, que sabe por declaracion de una muger gentil de nacion de los Comavos [...] y á esta muger llevamos al pueblo grande de San Miguel de los Conibos, donde declaró por interprete de un indio christiano nombrado Lorenzo de la ciudad de Quito, que le hallamos casi buelto gentil en el dicho pueblo de los Conibos, y hablava y entendia en la materna de la muger de nacion de los Comavos [...] y la declaracion de la muger se confirmó ser cierta por un indio gentil, principal de los Conibos, que assi mismo se hallo presente en la declaracion de la india, por haver estado cautivo en estas tierras de los Comavos por tiempo de seis años según su verdad; y este indio por nombre propio Pusinampa (Oliver, 1754: 70r).

Estas líneas indican no solamente que San Miguel de Conibos se convirtió en el sitio de acumulación de datos geográficos y cartográficos que permitieron la producción del mapa franciscano sino que la mujer anónima comavo, el indio intérprete Lorenzo y el principal conibo Pusinampay jugaron un rol importante en la transmisión y elaboración del conocimiento geográfico del Alto Ucayali. De esta manera, la configuración espacial de esta región por los expedicionarios hispanos dependió de las conexiones establecidas con nativos de Conibos.

Informantes nativos continúan apareciendo en el reporte del capitán Veraum como actores relevantes en el proceso de construcción del conocimiento del Alto Ucayali. Después de dejar el río Taraba, la expedición capturó momentáneamente dos indios mochovo cerca de la boca del río Ununi. A pesar que una visita propia a la comunidad de estos nativos no es descrita en el reporte, Veraum indicó que indios conibo habían informado a la expedición que los mochovo habitaban las selvas orientales de los Andes y que eran un pueblo numeroso (Oliver, 1754: 70v). La expedición siguió luego otro de los afluentes del Ucayali, el río Comarinigua. Esta vez ellos sí visitaron una comunidad habitada por unas cuarenta personas, cuyo curaca se llamaba Quicuruno o Quibruno. De acuerdo al padre Joseph Amich, Quicuruno era el líder de un subgrupo de nativos conibo que estaban aliados a un grupo campa, lo cual los mantenía separados de sus paisanos de San Miguel (Amich, 1854: 108-109). La expedición franciscana pasó dos días en este sitio, durante los cuales Quicuruno les proveyó de información sobre los comavo del río Taraba, los mochovo de los Andes orientales, así como de los robonagua, pichavo y soboivo (Oliver, 1754: 70v, 195r).

En Comarinigua, los padres dejaron fundada la misión de San Joseph. Luego la expedición navegó unas cincuenta leguas río abajo hasta San Miguel de Conibos. Allí estuvieron por veinticuatro días y conocieron al curaca Saniguani y a los otros principales del pueblo como Cayampay, y al intérprete Lorenzo, de quienes recibieron informaciones sobre la mayoría de las sociedades que habitaban el Alto Ucayali (Oliver, 1754: 71r). De esta manera, San Miguel de Conibos y San Joseph de Comarinigua se convirtieron en los dos únicos sitios que la expedición de 1686 visitó por un considerable lapso de tiempo. En consecuencia, el procesamiento de información y conocimiento sobre la ubicación de sociedades y territorios del Alto Ucayali, incluyendo aquellos que no fueron visitados por la expedición, fue resultado de los informantes nativos que hallaron en estos dos pueblos.

Si los pueblos de San Miguel y San Joseph se convirtieron en centros de recopilación de datos, los ríos a través de los cuales la expedición navegó fueron también sitios de producción de conocimiento en los cuales nativos conibo volvieron a jugar un rol importante. Ellos guiaron a los padres y soldados casi desde el inicio de la excursión, poco después de salir de San Luis de Perené. El capitán Fransisco Rojas señaló que luego de la confluencia de los ríos Perené y Taraba, la expedición se encontró con una flota de diez canoas con indios conibo. Ellos no solo se convertirían en guías sino que invitaron a los españoles a embarcarse en sus canoas para continuar el viaje hacia San Miguel (Oliver, 1754: 126v, 128r). El capitán Veraum indicó que en el viaje de regreso a San Luis de Perené la expedición fue acompañada por el curaca conibo Saniguani, los principales Cayampay, Sanampico y Pusinampay, más un grupo de sesenta y seis nativos en dieciocho canoas (Oliver, 1754: 71v). Entre los conibo, Felipe Cayampay tuvo un rol más importante como informante de la expedición franciscana. Rojas mencionó que, cuando estaban a punto de dejar San Miguel, él le pidió a Cayampay que identificara los nombres de los ríos y sociedades a lo largo del Ucayali «por quanto á la ida havia ido ciego, y sin tener quien me lo diesse á entender». El conocimiento provisto por Cayampay era considerado vital para la empresa franciscana puesto que él era «tan versado, y experimentado de todos los parages en 60 años que tenia, y corrido todas essas tierras muchissimas vezes» (Oliver, 1754: 141r).

Rojas estuvo también tomando notas del curso entero que había tomado la expedición desde que salieron de San Joseph hacia San Miguel, y el retorno a San Joseph. Él señaló que usó esas notas en su reporte y en el mapa presentado por los franciscanos (Oliver, 1754: 146v). Si Rojas estuvo registrando sus propias observaciones o las de Cayampay no es claro. Sin embargo, el capitán español subrayó la importancia del principal conibo en varias partes de su reporte. Durante el viaje de vuelta desde San Miguel, la expedición se detuvo esporádicamente en varios sitios donde fue posible observar y contactar algunas etnias como los mochovo del río Guanini (Oliver, 1754: 147r-149v). Al respecto, Rojas indicó que ellos ocuparon «esse dia [21 de octubre] en reconocer esse gentio, é informarnos de todo (aunque ya lo teniamos entendido) por havernos lo dicho el Caudillo ser muy copiosissima la dicha nacion» (Oliver, 1754: 149r). Entonces, a pesar del conocimiento adquirido intermitentemente en persona, la expedición tenía gran aprecio por la información que los conibo, en particular Felipe Cayampay, proveyeron acerca de los territorios y sociedades del Alto Ucayali.

¿Cuáles son las implicancias de esto para la configuración del conocimiento espacial del Ucayali? Significa que nativos conibo fueron la fuente de conocimiento más importante para la expedición franciscana de 1686. Los pueblos conibo de San Miguel y San Joseph, así como el viaje de regreso a San Luis de Perené acompañados 
de Cayampay, entre otros, se convirtieron en centros de configuración geográfica y cartográfica para el producto final que consistió en el mapa y los reportes presentados por los expedicionarios hispanos. Sin embargo, no fueron nativos conibo en general sino individuos o especialistas conibo en particular, como Pusinampay en su rol de intérprete de la anónima mujer comavo, así como Quicuruno en San Joseph y Cayampay en San Miguel quienes proveyeron las bases sobre las cuales los padres y capitanes españoles adquirieron y produjeron su conocimiento del Ucayali.

\section{CONCLUSIÓN}

A pesar del importante rol que los conibo jugaron en la exploración geográfica y construcción cartográfica del Alto Ucayali, ituvieron ellos alguna influencia en las negociaciones entre los franciscanos y jesuitas por esta región? Primero, con respecto a la resolución del litigio, los jesuitas nunca enviaron su reporte y mapa, como sí lo hicieron los franciscanos (Oliver, 1754: 32v)13. Sin embargo, los informes y mapas del gobernador de Lamas y del cura de Santiago de las Montañas proveyeron información de apoyo para la posición jesuita. Como resultado, el 24 de abril de 1687, el virrey del Perú decretó que la misión de San Miguel o Santisima Trinidad de Conibos quedaba bajo jurisdicción de la Sociedad de Jesús (Oliver, 1754: 33r)14. Esta situación formalizó en teoría la existencia de un límite entre las misiones jesuitas y franciscanas en el Ucayali. Esta decisión y el caso entero, no obstante, parecen ficticios. Las fuentes solo mencionan incursiones, a veces ocupaciones temporales del Alto Ucayali por miembros de estas dos órdenes. Sus mapas fueron más un proyecto que una verificación de los asentamientos misioneros'15. De este modo, la cesión de la misión de Conibos implicó no tanto una certificación de algo ya ocupado sino un permiso otorgado a los jesuitas para que iniciaran una ocupación efectiva del Alto Ucayali16.

${ }^{13}$ De acuerdo a la crónica del jesuita Juan de Velasco, Enrique Richter, quien se puso a cargo de la misión jesuita de Conibos en 1686, hizo un mapa del Ucayali. Sin embargo, cuando el pleito entre jesuitas y franciscanos empezó, Richter recién había iniciado su empresa misionera en el Ucayali. Así, su mapa no estuvo seguramente disponible para la resolución del litigio (Velasco, 1961, vol. 1 409-410).

${ }^{14}$ Según Antonino Tibesar, aunque los jesuitas nunca enviaron su mapa para la resolución final, las rentas superiores de dicha orden persuadieron a las autoridades virreinales para otorgarles la misión de San Miguel (Tibesar, 1989: 75, n. ${ }^{\circ}$ 135). Parece que Tibesar nunca vio el legajo que se discute aquí puesto que incluye los informes del gobernador de Lamas y del cura de Santiago de las Montañas quienes apoyaban la postura jesuita.

15 Sobre mapas como modelos para proyectos imperiales y/o estatales véanse Harley (2001: 57), Anderson (1991: 173).

${ }^{16}$ Esta ocupación nunca se llegó a materializar. Los padres Biedma y Richter, cabezas de los misioneros franciscanos y jesuitas en el Alto Ucayali, cayeron a manos de nativos en 1687 y 1695 respectivamente. Solo los franciscanos obtendrían una presencia más estable en la región hacia fines del siglo XVIII. Véanse Amich (1854: 120-122), Maroni (1988: 112), Velasco (1961, vol. 2: 770), Oliver (1754: 108r).
Nativos conibo, en cambio, habían habitado el Ucayali mucho antes de la llegada de los padres. Alrededor de la época del litigio jesuita-franciscano, ellos ya eran conocidos como los famosos navegantes guerreros del Ucayali (Varese, 2002: 68-69). Parece, sin embargo, que los franciscanos no se habían dado cuenta de los contactos previamente establecidos entre los conibo y los jesuitas (Morin, 1998: 304). Esta situación habría facilitado el aprovechamiento conibo de ambos grupos de foráneos quienes, viniendo tanto del norte como del sur, significaban la puerta de acceso a recursos no habidos en esta región17. En consecuencia, cuando el número de herramientas y otros productos traídos por uno de estos grupos de misioneros empezaba a decaer, era tiempo de recurrir al otro grupo por más provisiones. Esto ocurrió en octubre de 1686 cuando el padre Biedma y la expedición franciscana decidieron dejar San Miguel. Ellos señalaron que los nativos les habían mencionado que los jesuitas preparaban una expedición desde su misión de Cocama para restablecer sus posiciones en el Ucayali y castigar a aquellos indios que habían asesinado al hermano Herrera (Oliver, 1754: 23v-24r). No obstante, habían sido también nativos conibo quienes dieron al padre Richter la noticia del asesinato de su colega (Richter, 1686: 114). Los conibo entonces estaban orquestando de algún modo la migración de los misioneros a lo largo del Ucayali y estaban ellos convirtiendo a la misión de San Miguel en una zona de frontera para ambas órdenes religiosas. De este modo, si hubo una resolución final con respecto al límite entre las misiones jesuitas y franciscanas en el Ucayali, fue debido también a influencia coniba.

Rastrear y subrayar esta contribución coniba ha sido el objetivo de este artículo. Sin embargo, debe quedar claro que la cartografía y exploración del Ucayali así como el litigio jesuita-franciscano no fueron exclusivamente resultado de la participación de individuos conibo. La llegada de la expedición franciscana de 1686 trajo consigo la superposición de estructuras de poder nativas y foráneas. Esto significa que la participación de nativos conibo en la construcción cartográfica del Alto Ucayali no se puede analizar si no es como parte de la disputa que enfrentaba a agentes del imperio español en la Amazonía occidental. Ciertamente, es importante dejar en claro que no fueron los conibo en general sino ciertos expertos conibo como Cayampay y Quicuruno, entre otros, los productores del conocimiento espacial que los oficiales españoles y los misioneros franciscanos emplearon en su expedición al Alto Ucayali. Asimismo, se debe enfatizar que los pueblos de San Miguel de Conibos y San Joseph de Comarinigua se convirtieron en los centros de acumulación y organización de los datos que permitieron a la expedición franciscana conocer las sociedades y territorios del Ucayali. Sin embargo, en cuestión de fuentes, la contribución coniba solo puede ser evaluada a partir de los reportes y mapas producidos por los frailes y capitanes españoles quienes fueron los que finalmente procesaron el conocimiento espacial del

${ }^{17}$ En relación a los bienes, principalmente herramientas de hierro, que los nativos del Ucayali obtenian de los misioneros, véanse Oliver (1754: 23r), Myers (1974: 149, 153-154). Sobre el ro de los conibo como intermediarios en el Ucayali y su participación en el comercio de esclavos por herramientas, véase DeBoer (1986: 240-241). 
Ucayali. Además, en cuestión de análisis, la participación nativa se inserta dentro del contexto histórico marcado por la exploración del Ucayali en 1686. Los conibo aparecen como objetos de estudio inherentemente ligados a la expedición franciscana. Son partícipes, no creadores, de ella. Revalorizar la participación coniba en dicha empresa ha sido mi objetivo más importante. Sin embargo, no puede obviarse el contexto histórico más amplio. Por ello, la contribución más importante de este artículo es que la expedición franciscana al Ucayali en 1686 se entienda como el producto de performances no solo hispanas sino también indígenas.

\section{Siglas}

ALMREP (Archivo de Límites, Ministerio de Relaciones Exteriores del Perú, Lima) ARSI/AHJ (Archivum Romanun Societatis lesu, Archivo Histórico Javeriano, Bogotá) ASJQ (Archivo Sociedad de Jesús Quito, Biblioteca Aurelio Espinosa Polit, Quito)

\section{Referencias citadas}

AMICH, J., O. F. M., 1854 - Compendio histórico de los trabajos, sudores, fatigas, y muertes que los ministros evangélicos de la seráfica religión han padecido por la conversión de las almas de los gentiles, en las montañas de los Andes, pertenecientes a las provincias del Perú, 392 pp.; París: Librería de Rosa y Bouret.

ANDERSON, B., 1991 - Imagined Communities: Reflections on the Origin and Spread of Nationalism, 224 pp.; Londres: Verso.

ARBESMANN, R., 1945 - The Contribution of the Franciscan College of Ocopa in Peru to the Geographical Exploration of South America. The Americas, 1 (4): 393-417.

BARR, J., 2011 - Geographies of Power: Mapping Indian Borders in the 'Borderlands' of the Early Southwest. The William and Mary Quarterly, 68 (1): 5-46.

BIEDMA, M., O. F. M., 1981 - La conquista franciscana del Alto Ucayali (C. Milla Batres \& A. Tibesar, O. F. M., eds.), 187 pp.; Lima: Milla Batres.

BIEDMA, M., O. F. M. et al., 1989 - La conquista franciscana del Alto Ucayali (J. Heras, O. F. M. \& A. Tibesar, O. F. M., eds.), 292 pp.; Iquitos: Instituto de Investigaciones de la Amazonía Peruana, Centro de Estudios Teológicos de la Amazonía.

CERTEAU, M. de, 1984 - The Practice of Everyday Life, 229 pp.; Berkeley: University of California Press.

CRAIG, A., 1972 - Franciscan Exploration in the Central Montaña of Peru. In: Actas y memorias del XXXIX Congreso Internacional de Americanistas, vol. 4: 127-144 Lima: Instituto de Estudios Peruanos.

CUESTA, M., 1986 - Aportación franciscana a la geografía de América. Archivo ÍberoAmericano, 46: 535-576.

CUESTA, M., 1992 - Descubrimientos geográficos durante el s. XVIII: Acción franciscana en la ampliación de fronteras. Archivo Íbero-Americano, 52: 293-342.
CUESTA, M., 1997 - Pervivencia de modelos de exploración territorial tras la independencia de América del Sur. Archivo Íbero-Americano, 57: 498-506.

DEBOER, W., 1986 - Pillage and Production in the Amazon: A View through the Conibo of the Ucayali basin, Eastern Peru. World Archaeology, 18 (2): 231-246.

ESPINOZA, W. 2007 - Amazonía del Perú: Historia de la Gobernación y Comandancia General de Maynas (Hoy Regiones de Loreto, San Martín, Ucayali y Provincia de Condorcanqui): Del siglo XV a la primera mitad del siglo XIX, 598 pp.; Lima: Fondo Editorial del Congreso del Perú, Banco Central de Reserva del Perú, Promperú.

GRIDILLA, A., O. F. M., 1943 - Aportación de los Misioneros Franciscanos Descalzos al progreso de la Geografía del Perú. In: Un año en el Putumayo. Resumen de un diario (A. Gridilla, ed.): 63-90; Lima: Colección Descalzos.

HARLEY, J.B., 2001 - The New Nature of Maps: Essays in the History of Cartography (P. Laxton, ed.), 331 pp.; Baltimore: Johns Hopkins University Press.

HERAS, J., O. F. M. (ed.), 1979 - Informe del padre Manuel Biedma al Virrey del Perú, Marquez de la Palata. 1682 (I parte). Amazonía Peruana, 2 (4): 165-189.

HERAS, J., O. F. M., 1980 - Los Franciscanos de Ocopa y la cartografía regional del centro. Boletín de Lima, 6: 45-56.

HERAS, J., O. F. M. (ed.), 1980 - Informe del padre Manuel Biedma al Virrey del Perú, Marquez de la Palata. 1682 (II parte). Amazonía Peruana, 3 (5): 143-175.

HERAS, J., O. F. M. (ed.), 1985 - Viaje del P. Antonio Vital. Crónica que narra la entrada de P. Vital a las zonas habitadas por los Cunibos y Campas en 1687. Amazonía Peruana, 6 (12): 157-164.

HERAS, J., O. F M 1989 - Marco geográfico. In: La conquista franciscana del Alto Ucayali (J. Heras, O. F. M. \& A. Tibesar, O. F. M., eds.): 81-95; Iquitos: Instituto de Investigaciones de la Amazonía Peruana, Centro de Estudios Teológicos de la Amazonía.

HERAS, J., O. F. M., 1992 - Aporte de los Franciscanos a la Evangelización del Perú, 345 pp; Lima: Provincia Misionera de San Francisco Solano.

LUCERO, J., S. I., 1682 - Copia de carta del Padre Juan Lorenzo Luçero, Superior de las Missiones de los Maynas, escrita al Padre Juan Martinez Rubio, Provincial de la Provincia del Nuebo Reyno y Quito. Nueva Cartagena de Santiago de Xitipos y Santa Maria de Ucayalis, 20 de Febrero. In: ARSI/AHJ, N.R et Quit 15, 81-82v.

LUCERO, J., S. I., 1683 - Relación del Padre Juan Lorenzo Lucero sobre los Jívaros y otras reducciones del Amazonas. Laguna, 23 de Junio. In: ASJQ, leg. 5, doc. 450.

LUCERO, J., S. I., 1685 - Información judicial pedida por el Padre Lorenzo Lucero sobre que no hay minas de oro en el territorio de las Misiones que tiene la Compañía. San Francisco de Borja, 14 de Octubre. In: ASJQ, leg. 5, doc. 470.

MARONI, P., S. I., 1988 - Noticias auténticas del famoso río Marañón y misión apostólica de la Compañía de Jesús de la provincia de Quito (J.-P. Chaumeil, ed.), 565 pp.; lquitos: Instituto de Investigaciones de la Amazonía Peruana, Centro de Estudios Teológicos de la Amazonía.

MAÚRTUA, V. (ed.), 1907 - Juicio de límites entre el Perú y Bolivia. Contestación al alegato de Bolivia, vol. 6; Buenos Aires: Compañía Sud Americana de Billetes de Banco.

MORIN, F, 1998 - Los Shipibo-Conibo. In: Guía etnográfica de la alta Amazonía (F. Santos \& F. Barclay, eds.), vol. 3: 275-435; Panamá: Smithsonian Tropical Research Institute, Abya-yala, Instituto Francés de Estudios Peruanos. 
MUNDY, B., 1996 - The Mapping of New Spain: Indigenous Cartography and the Maps of the Relaciones Geográficas, 291 pp.; Chicago: University of Chicago Press.

MYERS, T., 1974 - Spanish Contacts and Social Change on the Ucayali River, Peru. Ethnohistory, 21 (2): 135-157.

OLIVER, A., O. F. M. (ed.), 1754 - Autos que se han seguido en este Gobierno y Acuerdo de Justicia de la ciudad de los Reyes sobre las jurisdiciones y linderos de las conversiones que tienen las dos religiones de Nuestro Padre San Francisco, y la Compañía de Jesús, esta por la provincia de Quito en los Maynas, gran Cocama y Omaguas; y la otra por la de Lima á Andamarca, y de alli para abajo por el gran rio Paro hasta las naciones de los Conibos, Callisecas, y Cepibos, donde se han encontrado por los años de 1687 á 24 de mayo. Marzo 1694. In: ALMREP, LEB-1147, caja 94, 1687-1694, 355ff.

RAIMONDI, A., 1876 - El Perú, vol. 2; Lima: Imprenta del Estado.

RICHTER, E., S. I., 1686 - El Padre Henrrique Richter al Padre Joseph Antonio Renteria. Dale noticia de la muerte del Hermano Francisco Herrera a manos de Campas. Laguna, 19 de Septiembre. In: ARSI/AHJ, N.R et Quit 15, 114-114v.

SHORT, J. R., 2009 - Cartographic Encounters: Indigenous Peoples and the Exploration of the New World, 176 pp.; Londres: Reaktion Books.

SOAREZ, A. G., 1686 - Testimonio authentico que da D. Antonio Garcia de Zoares, visitador general, del numero de almas que allo por los libros habian convertido y bautizado los nuestros en las Missiones del Marañon. Nueva Cartagena de Santiago de Xitipos, 30 de Mayo. In: ARSI/AHJ, N.R. et Quit 15, 135-140.

TIBESAR, A., O. F. M., 1989 - Introducción: la conquista del Perú y su frontera oriental. In: La conquista franciscana del Alto Ucayali (J. Heras, O. F. M. \& A. Tibesar, O. F. M., eds.): 15-79; Iquitos: Instituto de Investigaciones de la Amazonía Peruana, Centro de Estudios Teológicos de la Amazonía.

TODOROV, T., 1984 - The Conquest of America: The Question of the Other, 274 pp.; Nueva York: Harper \& Row.

VARESE, S., 2002 - Salt of the Mountain: Campa Asháninka History and Resistance in the Peruvian Jungle, 236 pp.; Norman: University of Oklahoma Press.

VELASCO, J. de, S.I., 1961 - Historia del Reino de Quito en la América Meridional (A. Espinosa Pólit, S. I., ed.), 2 vols.; Puebla: J.M. Cajica.

WHITEHEAD, N., 1998 - Indigenous Cartography in Lowland South America and the Caribbean. In: The History of Cartography (D. Woodward \& G. Malcolm Lewis, eds.), vol. 2, libro 3: 301-326; Chicago: University of Chicago Press. 